Published in final edited form as:

Angew Chem Int Ed Engl. 2016 July 25; 55(31): 9065-9069. doi:10.1002/anie.201603465.

\title{
Enantio- and Diastereoselective 1,2-Additions to a-Ketoesters with Diborylmethane and Substituted 1,1-Diborylalkanes
}

\author{
Stephanie A. Murray ${ }^{\ddagger}$, Jacob C. Green ${ }^{\ddagger}$, Sanita B. Tailor, and Simon J. Meek \\ Department of Chemistry, The University of North Carolina at Chapel Hill, Chapel Hill, NC \\ 27599-3290 (USA) \\ Simon J. Meek: sjmeek@unc.edu
}

\begin{abstract}
Catalytic enantioselective synthesis of boronate-substituted tertiary alcohols through additions of diborylmethane and substituted 1,1-diborylalkanes to a-ketoesters is reported. The reactions are catalyzed by readily available chiral phosphine-copper(I) complexes and produce $\beta$ hydroxyboronates containing up to two contiguous stereogenic centers in up to 99:1 er, and >20:1 dr. The utility of the organoboron products is demonstrated through several chemoselective functionalizations. Evidence indicates reactions occur via enantio-enriched a-boryl-Cu-alkyl intermediate.
\end{abstract}

\section{Graphical abstract}

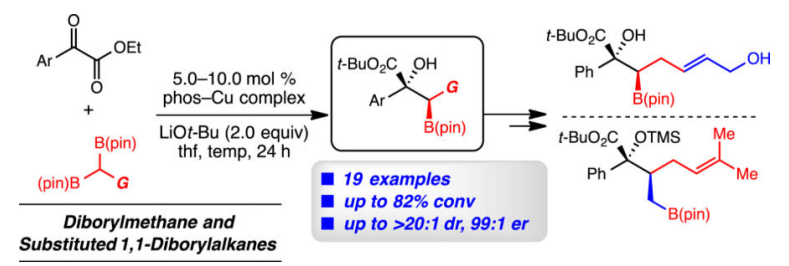

\begin{abstract}
Catalytic enantioselective synthesis of boronate-substituted tertiary alcohols through additions of diborylmethane and substituted 1,1-diborylalkanes to a-ketoesters is reported. The reactions are catalyzed by readily available chiral phosphine-copper(I) complexes and produce $\beta$ hydroxyboronates containing up to two contiguous stereogenic centers in up to 99:1 er, and >20:1 dr. The utility of the organoboron products is demonstrated through several chemoselective functionalizations. Evidence indicates reactions occur via enantio-enriched a-boryl-Cu-alkyl intermediate.
\end{abstract}

\section{Keywords}

diboron; 1,2-addition; copper; catalysis; enantioselective

\footnotetext{
Correspondence to: Simon J. Meek, s jmeek@unc. edu.

\$These authors contributed equally to this work.

Supporting information for this article is available on the WWW under http://dx.doi.org/10.1002/anie.201xxxxxx
} 
Tertiary alcohols are valuable functional groups found within many biologically active organic molecules. As a result, the development of efficient and selective methods for their preparation is an important challenge in organic chemistry. ${ }^{[1-2]}$ The catalytic addition of $\mathrm{sp}^{3}$ carbon-based nucleophiles to ketones provides one of the most efficient strategies to access enantiomerically enriched tertiary alcohols; ${ }^{[3]}$ nevertheless, despite recent progress in this area, a number of challenges still remain to be addressed. Of particular significance are protocols that deliver non-racemic tertiary alcohols and incorporate chemically versatile functional groups, such as alkyl boronic esters, for further manipulation. ${ }^{[4]}$ Stereoselective synthesis of $\beta$-boryl alcohols by the 1,2-addition of a-boryl alkyl nucleophiles provides a direct approach for the generation of such versatile chemical motifs. ${ }^{[5]}$ Catalytic methods of incorporating boronate esters via carbon-carbon bond formation remain limited, as current stoichiometric protocols involve the use of cuprate reagents ${ }^{[6]}$ and alkylation of reactive dimesityl boron-stabilized a-boryl carbanions. ${ }^{[7]}$ More recently, 1,1-organodiboronate esters have been developed as a-boryl carbanions in stereoselective deborylative carboncarbon bond forming reactions. ${ }^{[8]}$ Furthermore, catalytic enantioselective reactions that employ substituted 1,1-diborylalkanes are scarce. ${ }^{[8 \mathrm{~d}-\mathrm{e}, \mathrm{h}]}$, [5a]

We have shown that a-boryl-Cu species can be accessed through stereoselective deborylative transmetalation of 1,1-diboron compounds with $\mathrm{Cu}$-based catalysts. We recently demonstrated that such catalytically generated intermediates engage in 1,2additions for the enantio- and diastereoselective preparation of secondary alcohols bearing a vicinal boron-containing stereogenic center. ${ }^{[5]}$ We proposed that a similar strategy could be employed for the synthesis of tertiary alcohols containing 1,2-hydroxyboronates by adding to a-ketoesters. The difficulty of such a catalytic method arises from the ability to efficiently form a new $\mathrm{C}-\mathrm{C}$ bond between sterically congested vicinal $\mathrm{C}-\mathrm{sp}^{3}$ stereogenic centers.

Herein, we report the catalytic enantio- and diastereoselective synthesis of $\beta$-boryl tertiary alcohols through the $\mathrm{Cu}$-catalyzed additions of a-boryl nucleophiles to a-ketoesters. The utility of the products is illustrated through further alkyl boronate ester functionalizations (e.g., homologation, oxidation, and iodoetherification). Moreover, addition to a symmetrical ketone demonstrates the reaction occurs via the formation of a non-racemic a-boryl-Cualkyl intermediate.

We initiated our studies by evaluating the $\mathrm{Cu}$-catalyzed enantioselective addition of unsubstituted 1,1-diborylmethane (5) to different a-ketoesters (4a-c) (Table 1). We first examined the ability of the chiral $\mathrm{Cu}$ complex derived from commercially available monodentate $\mathbf{L 1}$, which had emerged as the optimal ligand for 1,2-additions involving aldehydes. ${ }^{[5]}$ We found that, with $5 \mathrm{~mol} \% \mathrm{Cu}(\mathrm{NCMe})_{4} \mathrm{PF}_{6}, 10 \mathrm{~mol} \% \mathbf{L 1}$, and 2.05 equiv $\mathrm{LiO} t$-Bu in thf at $22{ }^{\circ} \mathrm{C}$, the reaction proceeds to afford $43 \%$ conversion to $6 \mathbf{a}(91: 9 \mathrm{er})$ in 24 $\mathrm{h}$ and $24 \%$ eliminated product 7 (entry 1). At lower temperatures formation of boron-Wittig product 7 is suppressed, and the conversion to, and enantioselectivity of, 6a increases; for example, 6a is generated in $92: 8$ er and $96: 4$ er at $4{ }^{\circ} \mathrm{C}$ and $-10{ }^{\circ} \mathrm{C}$, respectively (entries 2 and 3). ${ }^{[9]}$ Entry 4 illustrates that the $\mathrm{Cu}(\mathrm{I})$-catalyzed reaction is less efficient at $-25^{\circ} \mathrm{C}$, furnishing $\mathbf{6 a}$ in $51 \%$ conversion and in $95: 5$ er. ${ }^{[10]}$ Remarkably, reaction of both the tertbutyl and methyl a-ketoesters $\mathbf{4 b}$ and $\mathbf{4 c}$, afford $\mathbf{6 a}$ in similar conversions (63\% and 70\%) and similar enantioselectivities (94:6 and 93:7 er respectively). These data indicate that (i) 
trans-esterification of $\mathbf{4 a}$ and $\mathbf{4 c}$, or the Et and Me ester products, occurs faster than 1,2addition (entries 3 and 6 vs 5), ${ }^{[9]}$ and (ii) $\mathrm{C}-\mathrm{C}$ bond formation occurs primarily through the $t$-Bu ester $\mathbf{4 b}$ (entry 3 vs 6 ). ${ }^{[11-12]}$ This is further supported by the reaction of ethyl ester $\mathbf{4 a}$ with one equivalent of $\mathrm{LiO} t$ - $\mathrm{Bu}$ (entry 7), which proceeds to $>98 \%$ conversion of $4 \mathbf{a}$ to afford $\beta$-boryl tertiary alcohol $\mathbf{6 a}\left(26 \%, 91: 9\right.$ er), and a-ketoester $\mathbf{4 b}(18 \%) .{ }^{[13]}$ Use of $\mathrm{NaO} t$-Bu results in a less efficient transformation (entry 8 ) as $\mathbf{6 a}$ is formed in $37 \% \mathrm{NMR}$ yield and 81:19 er. Further reaction optimization using various mono-and bidentate chiral phosphines did not result in a more efficient or stereoselective process (see Table 1). As there is minimal difference in reaction efficiency between $\mathbf{4 a - c}$, ethyl a-ketoesters were used for the remainder of the study due to their ready availability.

We began exploring the scope of the catalytic reaction by synthesizing various unsubstituted hydroxy boronates. Due to the varying stability of unsubstituted hydroxy boronates (e.g., 6a), the products were oxidized to the corresponding diol. Isolation and non-oxidative workup of the primary alkylboron products can be achieved through hydroxyl protection (vide infra). Using the optimal conditions in Table 1, the catalytic transformations can be performed with various aryl-substituted a-ketoesters (Table 2), including those that carry para $(\mathbf{8} \mathbf{a}-\mathbf{f})$, or meta $(\mathbf{8 g}-\mathbf{i})$ substituents. Transformations with electron-donating and electron-withdrawing groups proceed to similar ${ }^{1} \mathrm{H}$ NMR yields (58-82\%) and high enantioselectivities (92:8-97:3 e.r.) in $24 \mathrm{~h}$ at $-10{ }^{\circ} \mathrm{C}$. Only in the presence of $p$-MeOsubstituted phenyl a-ketoesters is a diminution in enantioselectivity observed; tertiary alcohol $\mathbf{8 b}$ (entry 2), is formed in $72 \%{ }^{1} \mathrm{H}$ NMR yield and 85:15 er. ${ }^{[14]}$ The transformation is sensitive to sterically congested a-ketoesters; 2-naphthyl proceeds to 70\% and 96:4 er (entry 10), while ortho-Me-substituted tertiary alcohol $\mathbf{8 k}$ is generated in $43 \%$ and $66: 34$ er (entry 11). Synthesis of pyridyl-substituted product $\mathbf{8 1}$ demonstrates that $\mathrm{N}$-heterocyclic aketoesters can serve as effective substrates, albeit oxidation to the corresponding diol proceeds with lower efficiency (entry 12).

Access to the $\beta$-boryl substituted products $\mathbf{6}$, can be easily achieved by protection of the tertiary alcohol as the silyl ether product prior to purification. The conversion of $4 \mathbf{a}$ into 9 in Eq 1 is representative; treatment of the crude product $6 \mathbf{a}(70 \% \text { conv) with ( } \mathrm{Me})_{3} \mathrm{SiCl}$ and imidazole ( $\mathrm{dmf}, 22{ }^{\circ} \mathrm{C}, 14 \mathrm{~h}$ ) affords alkylboronate (9) in $46 \%$ overall yield and 96:4 er after silica gel chromatography.
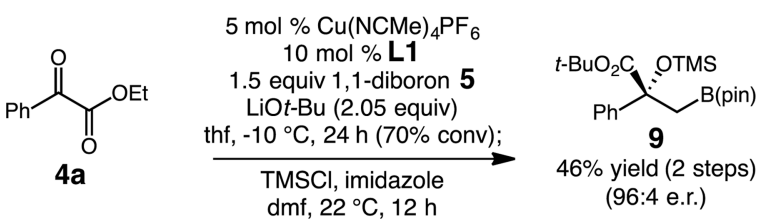

The $\mathrm{Cu}$-catalyzed protocol can be extended to more challenging processes that utilize substituted alkyl 1,1-diboron reagents to afford congested contiguous $3^{\circ}$ and $2^{\circ}$ stereogenic centers. Reactions require $10 \mathrm{~mol} \% \mathrm{Cu}$ catalyst derived from $\mathbf{L 1}$ or $\mathbf{L 2}$ at $22{ }^{\circ} \mathrm{C}$ to proceed to good conversion and high enantioselectivity. Notably, the secondary alkyl 
hydroxyboronate products are stable to silica gel column chromatography; for example, $\beta$ boryl tertiary alcohols containing silyl ether (11a), alkyl (11b-c), and alkenyl (11d-e) functional groups are isolated in up to $64 \%$ yield, $>20: 1 \mathrm{dr}$, and 99:1 er. The reaction is easily performed on gram scale; subjection of $1.0 \mathrm{~g}$ of $4 \mathbf{a}$ to $10 \mathbf{b}$ lead to the formation of $\mathbf{1 1 b}$ in $75 \%$ conversion $60 \%$ yield, $>20: 1 \mathrm{dr}$, and 98:2 er. The reaction of a gem-diboron reagent that contains an ester (e.g., 11f), although remarkably diastereo-(>20:1 dr) and enantioselective (94:6 er), results in only $40 \%{ }^{1} \mathrm{H}$ NMR yield after $24 \mathrm{~h}$; likely due to the presence of acidic a-protons. ${ }^{[15]}$ Increasing the size of the substituent proximal to the 1,1diboron group also results in decreased reactivity; under optimal conditions phenethyl containing $11 \mathrm{~g}$ is generated in 55\% yield ( $4: 1 \mathrm{dr}, 98: 2 \mathrm{er}$ ). The lack of formation ( $<5 \%$ conv) of benzyl $11 \mathrm{~h}$ highlights the sensitivity of the $\mathrm{Cu}$-catalyzed protocol to increased sterics of the substituted nucleophilic components. The absolute and relative stereochemistry of the 1,2-hydroxyboronates synthesized through the $\mathrm{Cu}$-catalyzed protocol was determined by $\mathrm{X}$ ray crystallographic analysis of tertiary alcohol $\mathbf{1 1 b}$ (Scheme 2). The stereochemical assignment of 11b is $(R, R)$ with an anti relationship between the hydroxyl and $\mathrm{B}(\mathrm{pin})$ units, corresponding to the addition of an $(R)$-alkyl copper species to the $S i$ face of the aketoester. ${ }^{16}$

The substituted organoboron compounds formed by the reported catalytic reaction can be transformed to afford a number of valuable enantio- and disastereoenriched molecules (Scheme 3a-d). Boron oxidation of 11a delivers trans diol $\mathbf{1 2}$ in $91 \%$ yield, which is equivalent to the dihydroxylation of a stereo-defined tri-substituted alkene. While the secondary alkyl B(pin) functional groups synthesized through the $\mathrm{Cu}$-catalyzed protocol (e.g., 13) proved to be unsuitable reagents for Pd-catalyzed cross-coupling, ${ }^{[17]}$ they readily participate in metal-free homologations. Sterically hindered secondary alkyl B(pin) silyl ether 13 (formed in 60\% yield) undergoes stereospecific $\mathrm{C}-\mathrm{B}$ to $\mathrm{C}-\mathrm{C}$ conversion, to afford primary alkylboron tertiary silyl ether $\mathbf{1 4}$ in $50 \%$ yield. The functional group rich organoboron molecules can also be chemoselectively functionalized leaving the $\mathrm{C}\left(\mathrm{sp}^{3}\right)-\mathrm{B}$ bond intact. As illustrated in Scheme 3c, allyl substituted hydroxyboronate 11c undergoes efficient cross-metathesis; ${ }^{[18]}$ in the presence of 10 mol \% ruthenium catalyst $\mathbf{1 7}$ and 2 equivalents of cis-alkene 15, allylic alcohol 16 is formed in $63 \%$ yield and 16:1 E/Z. Additionally, the prenyl-substituted $\beta$-boryl tertiary alcohols can be readily converted to tetrahydropyrans via iodoetherification ${ }^{[19]}$ without loss of the $\mathrm{B}$ (pin) unit; treatment of 11d with $\mathrm{I}_{2}$ and $\mathrm{NaHCO}_{3}$ at $-35{ }^{\circ} \mathrm{C}$ in $\mathrm{MeCN}$ for $2 \mathrm{~h}$ furnishes substituted tetrahydropyran 18 in $56 \%$ conversion and 3:1 dr, and silica gel purification delivers 18 as a single diastereoisomer in $45 \%$ yield.

A proposed catalytic reaction sequence for the $\mathrm{Cu}$-catalyzed process is outlined in Scheme 4. Enantioselective transmetalation between a $\mathrm{Cu}$-alkoxide $(\mathbf{A})$ and 1,1-diboron 1, generates chiral a-boryl-alkyl-Cu B. Stereoselective 1,2-addition to a-ketoester $\mathbf{2}$ affords $\mathrm{Cu}$-alkoxide C containing two contiguous stereogenic centers. Reaction with $\mathrm{LiO} t$-Bu furnishes the lithium alkoxide product $\mathbf{D}$, which is converted to $\mathbf{3}$ after acid workup, and regenerates copper catalyst $\mathbf{A}$. 
While the chiral phosphine-copper catalyst controls addition of the a-boryl-Cu intermediate to the $\mathrm{Si}$ face of the a-ketoester $(\mathbf{B} \rightarrow \mathbf{C})$ for diborylmethane, and substituted variants, it is unclear if substituted 1,1-diborons react through an enantio-enriched $(R)$-a-boryl-Cu-alkyl nucleophile (e.g., B R=Me, Scheme 4). To gain insight into the formation of an enantioenriched a-boryl-Cu-alkyl intermediate we examined the Cu-catalyzed 1,2-addition of $\mathbf{1 0 b}$ to a symmetrical carbonyl electrophile (Equation 2). Treatment of benzophenone (19) with 10b under optimal reaction conditions in Scheme $2\left(10 \mathrm{~mol} \%(\mathbf{L 1})_{2} \mathrm{CuO} t-\mathrm{Bu}\right)$, affords $(R)-20$ in $42 \%{ }^{1} \mathrm{H}$ NMR yield and 97:3 er. ${ }^{20}$ This result indicates that the sterocenter of the a-boryl-Cu-alkyl nucleophile is formed in high er, and that the catalyst functions to control both the formation of the $\mathrm{Cu}$-alkyl and the facial selectivity. ${ }^{21}$

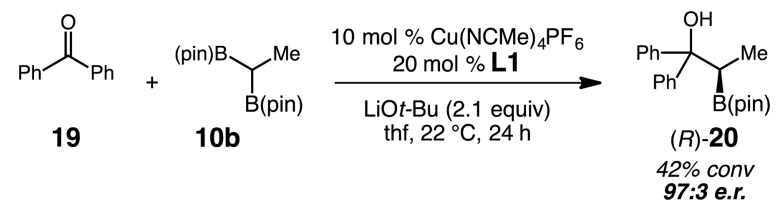

In summary, we present the first catalytic protocol for the enantio- and diastereoselective synthesis of $\beta$-boryl tertiary alcohols. The approach is applicable to diboroylmethane and other readily accessible substituted 1,1-diborylalkanes, and a-ketoesters. Reactions are promoted by a phosphine-Cu complex and proceed via 1,2-addition of a-boryl nucleophiles to generate up to two contiguous stereogenic centers. The versatility of the $\beta$-boryl tertiary alcohol products synthesized is underlined by representative stereospecific and chemoselective functionalizations to provide useful chemical fragments. Further mechanistic studies, application to multistep complex molecule syntheses, and the development of related stereoselective catalytic reactions are in progress.

\section{Supplementary Material}

Refer to Web version on PubMed Central for supplementary material.

\section{Acknowledgments}

Financial support was provided by the United States National Institutes of Health, Institute of General Medical Sciences (GM-116987) and the University of North Carolina at Chapel Hill.

\section{References}

1. Quaternary Stereocenters: Challenges and Solutions for Organic Synthesis; Christophers J, Baro A. 2006WeinheimWiley-VCH

2. For recent reviews on catalytic enantioselective additions to ketones, see: Riant O, Hannedouche J. Organic \& Biomolecular Chemistry. 2007; 5(6):873. [PubMed: 17340001] Shibasaki M, Kanai M. Chem. Rev. 2008; 108:2853-2873. [PubMed: 18570481]

3. For representative examples of catalytic enantioselective additions of $\mathrm{sp}^{3}$ carbon-based nucleophiles to ketones, see: García C, LaRochelle LK, Walsh PJ. J. Am. Chem. Soc. 2002; 124:10970-10971. [PubMed: 12224931] DiMauro EF, Kozlowski MC. J. Am. Chem. Soc. 2002; 124:12668-12669. [PubMed: 12392407] Funabashi K, Jachmann M, Kanai M, Shibasaki M. Angew. Chem. Int. Ed. 2003; 42:5489-5492. Angew. Chem2003, 115, 5647-5650. Betancort JM, García C, Walsh PJ. 
Synlett. 2004; 5:749-760. Siewert J, Sandmann R, von Zezschwitz P. Angew. Chem. Int. Ed. 2007; 46:7122-7124. Angew. Chem. 2007, 119, 7252-7254. Hatano M, Miyamoto T, Ishihara K. Org. Lett. 2007; 9:4535-4538. [PubMed: 17902685] Friel DK, Snapper ML, Hoveyda AH. J. Am. Chem. Soc. 2008; 130:9942-9951. [PubMed: 18588297] Madduri AVR, Harutyunyan SR, Minnaard AJ. Angew. Chem. Int. Ed. 2012; 51:3164-3167. Angew. Chem. 2012, 124, 3218-3221. Rong J, Pellegrini T, Harutyunyan SR. Chem. Eur. J. 2016; 22:3558-3570. [PubMed: 26511715]

4. Winbush SM, Roush WR. Org. Lett. 2010; 12:4344-4347. [PubMed: 20806914] Blaisdell TP, Caya TC, Zhang L, Sanz-Marco A, Morken JP. J. Am. Chem. Soc. 2014; 136:9264-9267. [PubMed: 24941137] Blaisdell TP, Morken JP. J. Am. Chem. Soc. 2015; 137:8712-8715. [PubMed: 26125083] For a recent in direct approach to 1,2-hydroxyborons, see: Chen D, Zhang X, Qi W-Y, Xu B, Xu M-H. J. Am. Chem. Soc. 2015; 137:5268-5271. [PubMed: 25726987]

5. Joannou MV, Moyer BS, Meek SJ. J. Am. Chem. Soc. 2015; 137:6176-6179. [PubMed: 25905917] (b) Joannou MV, Moyer BS, Goldfogel MJ, Meek SJ. Angew. Chem. Int. Ed. 2015; 54:1414114145. Angew. Chem. 2015, 127, 14347-14351.

6. (a) Knochel P. J. Am. Chem. Soc. 1990; 112:7431-7433.(b) Sakai M, Saito S, Kanai G, Suzuki A, Miyaura N. Tetrahedron. 1996; 52:915-924.

7. Pelter A, Peverall S, Pitchford A. Tetrahedron. 1996; 52:1085-1094.

8. Endo K, Ohkubo T, Hirokami M, Shibata T. J. Am. Chem. Soc. 2010; 132:11033-11035. [PubMed: 20698667] Endo K, Ohkubo T, Shibata T. Org. Lett. 2011; 13:3368-3371. [PubMed: 21644527] Endo K, Ohkubo T, Ishioka T, Shibata T. J. Org. Chem. 2012; 77:4826-4831. [PubMed: 22540212] Sun C, Potter B, Morken JP. J. Am. Chem. Soc. 2014; 136:6534-6537. [PubMed: 24564423] Potter B, Szymaniak AA, Edelstein EK, Morken JP. J. Am. Chem. Soc. 2014; 136:17918-17921. [PubMed: 25482206] Hong K, Liu X, Morken JP. J. Am. Chem. Soc. 2014; 136:10581-10584. [PubMed: 25019925] Coombs JR, Zhang L, Morken JP. J. Am. Chem. Soc. 2014; 136:16140 16143. [PubMed: 25387002] Sun HY, Kubota K, Hall DG. Chem. Eur. J. 2015; 21:1-10. Kim J, Park S, Park J, Cho SH. Angew. Chem. Int. Ed. 2016; 55:1498-1501. Angew. Chem. 2016, 128, 1520-1523. Shi Y, Hoveyda AH. Angew. Chem. Int. Ed. 2016; 55:3455-3458. Angew. Chem. 2016, 128, 3516-3519. Zhang Z-Q, Zhang B, Lu X, Liu J-H, Lu X-Y, Xiao B, Fu Y. Org. Lett. 2016; 18:952-955. [PubMed: 26872072] Park J, Lee Y, Kim J, Cho SH. Org. Lett. 2016; 18:1210-1213. [PubMed: 26900647] Zhan M, Li R-Z, Mou Z-D, Cao C-G, Liu J, Chen Y-W, Niu D. ACS Catal. 2016; 6:3381-3386. For recent syntheses of 1,1-alkylbisboronate esters, see: Zhang Z-Q, Yang C-T, Liang L-J, Xiao B, Lu X, Liu J-H, Sun Y-Y, Marder TB, Fu Y. Org. Lett. 2014; 16:6342-6345. [PubMed: 25436511] Batsanov AS, Cabeza JA, Crestani MG, Fructos MR, García-Álvarez P, Gille M, Lin Z, Marder TB. Angew. Chem. Int. Ed. 2016; 55:4707-4710. Angew. Chem. 2016, 128, 4785-4788. Cook AK, Schimler SD, Matzger AJ, Sanford MS. Science. 2016; 351:1421-1424. [PubMed: 27013725] Smith KT, Berritt S, González-Moreiras M, Ahn S, Smith MR III, Baik M-H, Mindiola DJ. Science. 2016; 351:1424-1427. [PubMed: 27013726]

9. Absolute stereochemistry of tertiary alcohol 6a formed with $(R)$-MonoPhos is $(R)$ (see Supporting Information).

10. Reactions run for $48 \mathrm{~h}$ at $-25^{\circ} \mathrm{C}$ did not lead to an increase in yield.

11. Treatment of $\mathbf{4 a}$ with 2 equivalents of $\mathrm{LiO} t-\mathrm{Bu}$ (no $\mathrm{Cu}$ or $\mathbf{L 1}$ ) at $-10^{\circ} \mathrm{C}$ for $2.5 \mathrm{~h}$ results in $>98 \%$ conversion of $\mathbf{4 a}$ and $90 \%$ conversion to 6 . Treatment of $\mathbf{4 a}$ with 2 equivalents of $\mathrm{LiO} t$-Bu, $5 \mathrm{~mol}$ $\% \mathrm{Cu}(\mathrm{NCMe})_{4} \mathrm{PF}_{6}$, and $\left.10 \mathrm{~mol} \% \mathbf{L 1}\right)$ at $-10{ }^{\circ} \mathrm{C}$ for $2.5 \mathrm{~h}$ results in $>98 \%$ conversion of $4 \mathbf{a}$ but only $70 \%$ to 6.

12. For an example of $\mathrm{Cu}(\mathrm{I})$-catalyzed trans-esterification, see: Munro-Leighton $\mathrm{C}$, Delp SA, Blue ED, Gunnoe TB. Organometallics. 2007; 26:1483-1493.

13. Decreased er is likely due to reaction with LiOEt.

14. The lower enantioselectivity of $\mathbf{9 b}$ is not due to partial racemization during purification; resubjection of $\mathbf{9 b}$ to silica column chromatography affords $\mathbf{9 b}$ in 85:15 er.

15. Increasing the equivalents of $\mathrm{LiOt}-\mathrm{Bu}$ or decreasing the reaction temperature does not improve conversion to $\mathbf{1 0 e}$.

16. For examples of stereoretentive reactions of organocopper-alkyls, see: Campbell MJ, Johnson JS. Org. Lett. 2007; 9:1521-1524. [PubMed: 17362022] Lee Y, Hoveyda AH. J. Am. Chem. Soc. 2009; 131:3160-3161. [PubMed: 19256564] Zhong C, Kunii S, Kosaka Y, Sawamura M, Ito H. J. Am. Chem. Soc. 2010; 132:11440-11442. [PubMed: 20684557] Matsuda N, Hirano K, Satoh T, 
Miura M. J. Am. Chem. Soc. 2013; 135:4934-4937. [PubMed: 23495912] Jia T, Cao P, Wang B, Lou Y, Yin X, Wang M, Liao J. J. Am. Chem. Soc. 2015; 137:13760-13763. [PubMed: 26458555] Yang Y, Shi S-L, Niu D, Liu P, Buchwald SL. Science. 2015; 349:62-66. [PubMed: 26138973] For an example stereoinvertive reactions of organocopper-alkyls, see: (g) ref 16c Logan KM, Smith KB, Brown MK. Angew. Chem. Int. Ed. 2015; 54:5228-5231. Angew. Chem. 2015, 127, 53175320.

17. Steric hinderance of the $1^{\circ}$ and $2^{\circ}$ alkyl boronic esters likely inhibits reaction.

18. Connon SJ, Blechert S. Angew. Chem. Int. Ed. 2003; 42:1900-1923. Angew. Chem. 2003, 115, 1944-1968.

19. Kumar S, Kaur P, Mittal A, Singh P. Tetrahedron. 2006; 62:4018-4026.

20. $24 \%$ unreacted benzophenone; Er determined by conversion to the known corresponding diol (see Supporting Information for details)

21. Studies to elucidate the boron enantiotopic group-selectivity during transmetalation are on going. 
a. Previous Work:

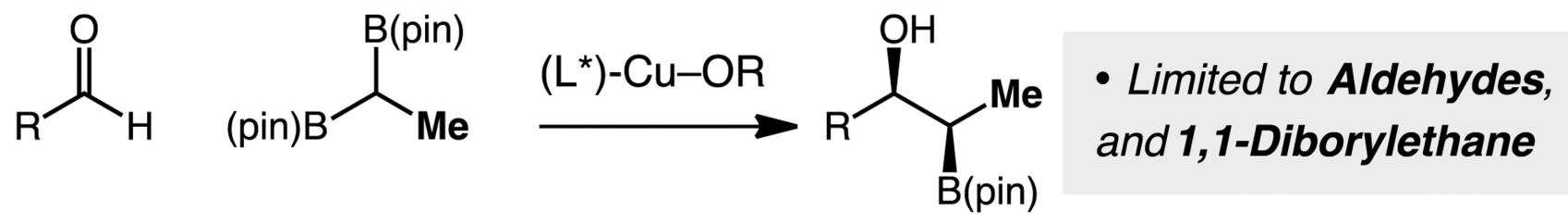

b. This Work:<smiles>[R]C(=O)C(=O)OCC</smiles><smiles>[Hg]C([Hg])[Hg]</smiles>
$G=H$, alkyl

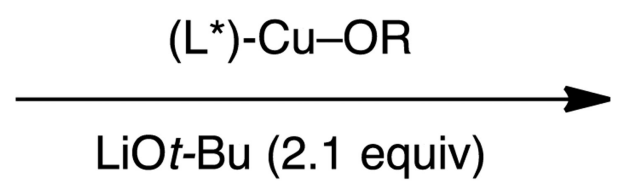<smiles>[R5]OC(=O)[C@](O)([18OH])[C@H]([10BH2])C</smiles>

- $\alpha$-Ketoesters - Diborylmethane - Several Substituted 1,1-Diborylalkanes

\section{- Enantio-enriched $\alpha$-Boryl-Cu Nucleophile}

Scheme 1.

Previous work: a. Catalytic enantio- and diastereoselective 1,2-addition of 1,1-diborylethane to aldehydes. This work: b. Catalytic enantio- and diastereoselective 1,2-addition of 1,1diborylmethane and functionalized 1,1-diborylalkanes to a-ketoesters. 


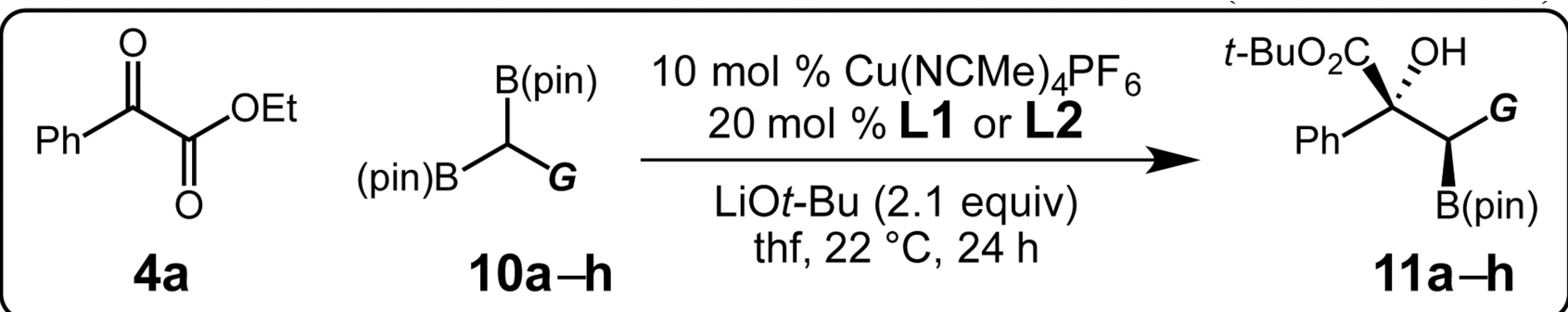

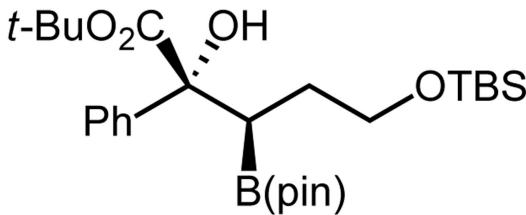

$11 \mathrm{a}$

L2: $72 \%$ conv, $51 \%$ yield 3.3:1 dr, 98:2 er<smiles>C=CC[C@@H](Br)[C@](O)(C(=O)OC(C)(C)C)c1ccccc1</smiles>

$11 \mathrm{c}$

L2: $62 \%$ conv, $50 \%$ yield $>20: 1 \mathrm{dr}, 99: 1 \mathrm{er}$<smiles>CC(C)(C)OC(=O)C[C@H](Br)[C@@](O)(c1ccccc1)[PH](C)(C)C</smiles>

$11 f$

L2: $40 \%$ yield[d] $>20: 1 \mathrm{dr}, 94: 6$ er<smiles>CC(C)(C)OC(=O)[C@](O)(c1ccccc1)[C@H]([18OH])Br</smiles>

$11 \mathrm{~b}$

L1: $75 \%$ conv, $64 \%$ yield $>20: 1 \mathrm{dr}, 98: 2$ er (1.0 g scale; 60\% yield)<smiles>CC(C)=CCC(Br)[C@@](O)(C(=O)OC(C)(C)C)c1ccccc1</smiles>
11d

L2: $70 \%$ conv, $60 \%$ yield 7.3:1 dr, 99:1 er X-ray
Structure
of $11 \mathbf{b}$ Qf 1<smiles>CCC[C@H](Br)[C@](O)(C(=O)OC(C)(C)C)c1ccccc1</smiles>

$11 \mathrm{e}$

L2: $45 \%$ conv, $30 \%$ yield 3.5:1 dr, 98:2 er<smiles>CC(C)(C)OC(=O)[C@](O)(c1ccccc1)[C@H](Br)CCc1ccccc1</smiles>

$11 \mathrm{~g}$

L2: $55 \%$ yield[d]<smiles>CC(C)(C)OC(=O)[C@](O)(c1ccccc1)[C@H](Br)Cc1ccccc1</smiles>

$11 \mathrm{~h}$ $<5 \%$ conv

Scheme 2.

Enantio- and Diastereoselective Addition of Substituted 1,1-Diboronates to a-Ketoesters. [a] [a-c] See Table 1. [d] 'H NMR yield. L2 = (R)-(+)-5,5',6,6', 7,7',8,8' -octahydro-1,1'-bi-2naphthol derived MonoPhos. 
a. Oxidation:

$t-\mathrm{BuO}_{2} \mathrm{C}, \mathrm{OH}$<smiles>C[C@H](CCO[Sb-])[C@H](Br)c1ccccc1</smiles>
$B($ pin)

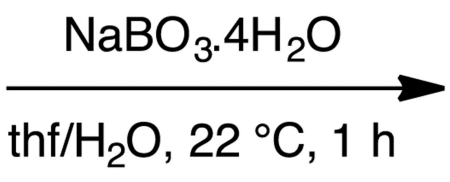

$91 \%$ yield
$t-\mathrm{BuO}_{2} \mathrm{C}$<smiles>C[C@@H](c1ccccc1)[C@@H](O)CC[OH+]</smiles>

12

b. Homologation:

$t-\mathrm{BuO}_{2} \mathrm{C}$.TTMS

$\mathrm{Ph}$<smiles>C1CC[Pb]C1</smiles>

$B$ (pin)

13

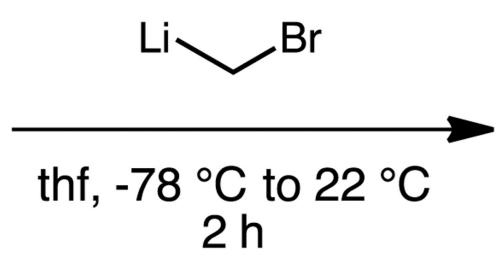

(TMS formation: $60 \%$ yield)

\section{Cross-Metathesis:}

$t-\mathrm{BuO}_{2} \mathrm{C}_{2}, \mathrm{OH}$<smiles>C=CC[C@@H](Br)C(C)c1ccccc1</smiles>

$11 \mathrm{C}$

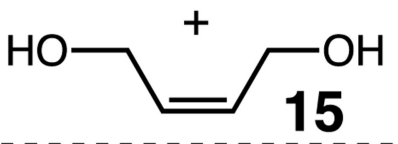

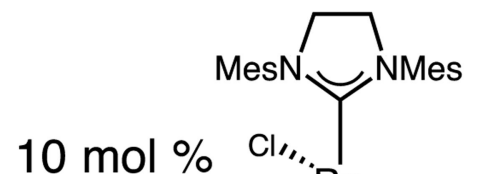

$10 \mathrm{~mol} \% \mathrm{Cl}_{2}$

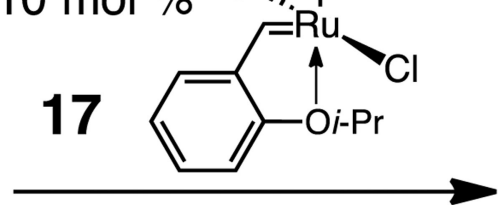

thf, $40^{\circ} \mathrm{C}, 4 \mathrm{~h}$
$t-\mathrm{BuO}_{2} \mathrm{C}$, OTMS<smiles>CC(C)=CC[C@@H](CBr)C(C)(c1ccccc1)c1ccccc1</smiles>

14
$t-\mathrm{BuO}_{2} \mathrm{C}_{1} \mathrm{OH}$<smiles>OC/C=C/C[C@H](Br)[C](Cc1ccccc1)c1ccccc1</smiles>

d. Tetrahydropyran Synthesis:<smiles>CC(C)=CC[C@@H](Br)[C@](O)(C(=O)O[Mg])c1ccccc1</smiles>

11d

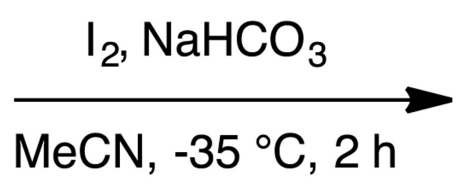

(pin)B

$56 \%$ conv, 3:1 dr

(45\% yield of isolated 18$)$

Scheme 3.

Representative Functionalizations of a-Boryl Tertiary Alcohols. 


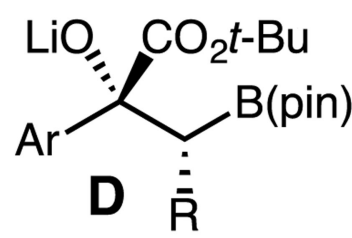

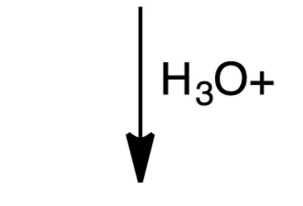

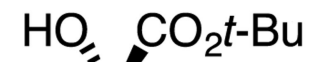<smiles>[2H]C(Br)[C@@](C)(CCCCC)[Hg]Br</smiles><smiles>CCC(C)C(C)Br</smiles>
(L) $\mathrm{Cu}-\mathrm{Ot}-\mathrm{Bu}$
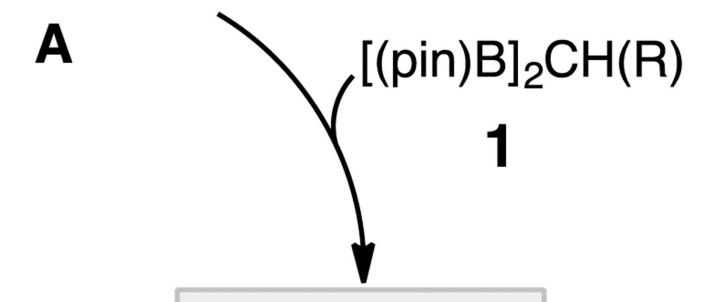

$\overline{\mathrm{R}}$

3

(R)-L1-Cu controls facial selectivity<smiles>[2H][C@H](Br)[C@@](Br)(OC)C(=O)OC</smiles>

A

3

Scheme 4.

Working Catalytic Cycle for $\mathrm{Cu}$-Catalyzed 1,2-Addition. 

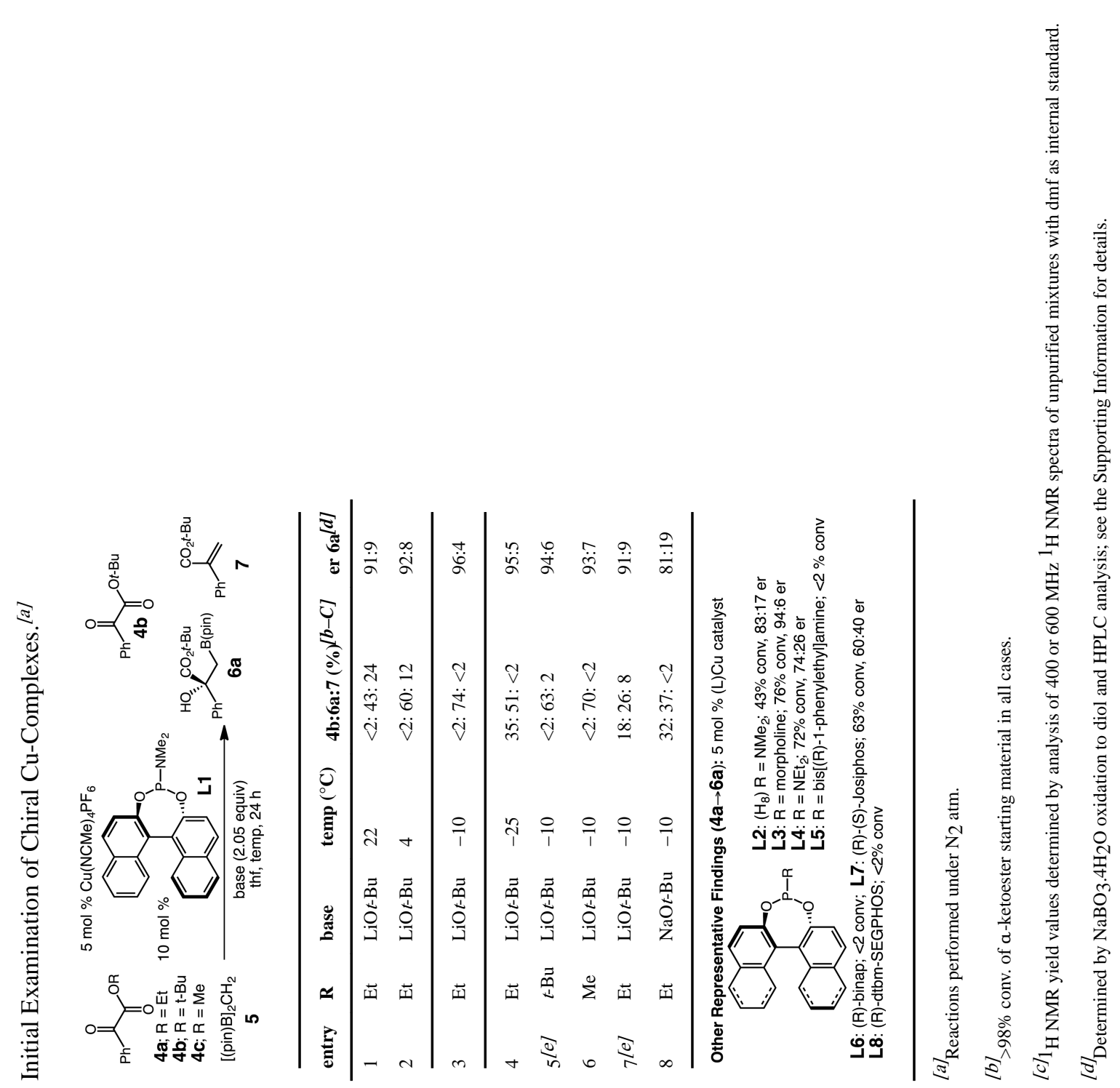

Angew Chem Int Ed Engl. Author manuscript; available in PMC 2017 July 25. 


\section{Table 2}

$\mathrm{Cu}(\mathrm{I})$-Catalyzed 1,2-Addition of 1 to Aryl a-Ketoesters. ${ }^{[a]}$

\begin{tabular}{|c|c|c|c|c|}
\hline $\begin{array}{r}\mathrm{C}(\mathrm{pin}) \mathrm{B}] \\
\mathbf{5}\end{array}$ & 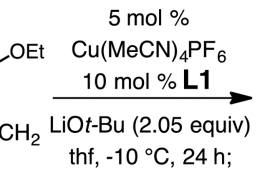 & $\mathrm{CO}_{2} t-\mathrm{Bu}$ & $\underset{\mathrm{H}_{2} \mathrm{O}}{\stackrel{\mathrm{BO}_{3}}{\longrightarrow}}$ & \\
\hline entry & product & $\begin{array}{l}{ }^{1} \mathrm{H} \text { NMR yield } \\
\text { of } 6(\%)^{[b-C]}\end{array}$ & $\begin{array}{l}\text { yield of } 8 \\
(\%)^{[d]}\end{array}$ & $\mathrm{er}^{[e]}$ \\
\hline 1 & $\mathbf{8 a} ; \mathrm{Ar}=\mathrm{Ph}$ & 74 & 65 & $96: 4$ \\
\hline 2 & $\mathbf{8 b} ; \mathrm{Ar}=p-\mathrm{OMeC}_{6} \mathrm{H}_{4}$ & 72 & 60 & $85: 15$ \\
\hline 3 & $\mathbf{8 c} ; \mathrm{Ar}=p-\mathrm{CIC}_{6} \mathrm{H}_{4}$ & 80 & 64 & $97: 3$ \\
\hline 4 & $\mathbf{8 d} ; \mathrm{Ar}=p-t-\mathrm{BuC}_{6} \mathrm{H}_{4}$ & 77 & 70 & $92: 8$ \\
\hline 5 & $\mathbf{8 e} ; \mathrm{Ar}=p-\mathrm{NO}_{2} \mathrm{C}_{6} \mathrm{H}_{4}$ & 62 & 46 & $94: 6$ \\
\hline 6 & $\mathbf{8 f} ; \mathrm{Ar}=p-\mathrm{CF}_{3} \mathrm{C}_{6} \mathrm{H}_{4}$ & 58 & 54 & $97: 3$ \\
\hline 7 & $\mathbf{8 g} ; \mathrm{Ar}=m-\mathrm{MeC}_{6} \mathrm{H}_{4}$ & 76 & 63 & $96: 4$ \\
\hline 8 & $\mathbf{8 h} ; \mathrm{Ar}=m-\mathrm{OMeC}_{6} \mathrm{H}_{4}$ & 82 & 62 & $96: 4$ \\
\hline 9 & $\mathbf{8 i} ; \mathrm{Ar}=m-\mathrm{CIC}_{6} \mathrm{H}_{4}$ & 81 & 64 & $97: 3$ \\
\hline 10 & $\mathbf{8 j} ;$ Ar = 2-napthyl & 70 & 62 & $96: 4$ \\
\hline 11 & $\mathbf{8 k} ; \mathrm{Ar}=o-\mathrm{MeC}_{6} \mathrm{H}_{4}$ & 43 & 27 & $66: 34$ \\
\hline 12 & 8I; Ar = 3-pyridyl & 72 & 36 & $97: 3$ \\
\hline
\end{tabular}

${ }^{[a-c]}$ See Table 1.

${ }^{[d]}$ Yields of the corresponding purified diol; yields are an average of two runs.

${ }^{[e]}$ Determined by HPLC analysis; see the Supporting Information for details. 